\title{
Individual Versus Team-Based Financial Incentives to Increase Physical Activity: A Randomized, Controlled Trial
}

\author{
Mitesh S. Patel, MD, MBA, MS 1,2,3,4,5, David A. Asch, MD, MBA 1,2,3,4,5, Roy Rosin, MBA4, \\ Dylan S. Small, $P h D^{2}$, Scarlett L. Bellamy, $S C D^{7}$, Kimberly Eberbach, MA ${ }^{6}$, Karen J. Walters, MBA' \\ Nancy Haff, $M D^{7}$, Samantha M. Lee, $B S E^{8}$, Lisa Wesby, $M S^{3}$, Karen Hoffer, BS ${ }^{3}$, \\ David Shuttleworth, $\mathrm{MS}^{3}$, Devon $H$. Taylor, $B S^{3}$, Victoria Hilbert, $M P H, R D^{3}$, Jingsan Zhu, MBA, $M S^{3}$, \\ Lin Yang, $M S^{3}$, Xingmei Wang, $M S^{3}$, and Kevin G. Volpp, $M D, P h D^{1,2,3,4,5}$
}

\begin{abstract}
'Perelman School of Medicine, University of Pennsylvania, Philadelphia, PA, USA; ${ }^{2}$ The Wharton School, University of Pennsylvania, Philadelphia, PA, USA; ${ }^{3} \mathrm{LDI}$ Center for Health Incentives and Behavioral Economics, University of Pennsylvania, Philadelphia, PA, USA; ${ }^{4}$ Penn Medicine Center for Health Care Innovation, Philadelphia, PA, USA; ${ }^{5}$ Crescenz Veterans Affairs Medical Center, Philadelphia, PA, USA; ${ }^{6}$ Independence Blue Cross, Philadelphia, PA, USA; ${ }^{7}$ Department of Medicine, Massachusetts General Hospital, Boston, MA, USA; ${ }^{8}$ Columbia University Medical Center, New York, NY, USA.
\end{abstract}

BACKGROUND: More than half of adults in the United States do not attain the minimum recommended level of physical activity to achieve health benefits. The optimal design of financial incentives to promote physical activity is unknown.

OBJECTIVE: To compare the effectiveness of individual versus team-based financial incentives to increase physical activity.

DESIGN: Randomized, controlled trial comparing three interventions to control.

PARTICIPANTS: Three hundred and four adult employees from an organization in Philadelphia formed 76 four-member teams.

INTERVENTIONS: All participants received daily feedback on performance towards achieving a daily 7000 step goal during the intervention (weeks 113) and follow-up (weeks 14-26) periods. The control arm received no other intervention. In the three financial incentive arms, drawings were held in which one team was selected as the winner every other day during the 13-week intervention. A participant on a winning team was eligible as follows: \$50 if he or she met the goal (individual incentive), \$50 only if all four team members met the goal (team incentive), or $\$ 20$ if he or she met the goal individually and \$10 more for each of three teammates that also met the goal (combined incentive).

MAIN MEASURES: Mean proportion of participantdays achieving the 7000 step goal during the intervention.

KEY RESULTS: Compared to the control group during the intervention period, the mean proportion achieving the 7000 step goal was significantly greater for the combined incentive $(0.35$ vs. 0.18 , difference: $0.17,95 \%$ confidence interval [CI]: $0.07-0.28, p<0.001)$ but not for the individual incentive $(0.25$ vs 0.18 , difference: $0.08,95 \%$ CI: $-0.02-0.18, p=0.13)$ or the team incentive $(0.17$ vs

Received July 10, 2015

Revised November 16, 2015

Accepted February 1, 2016

Published online March 14, 2016
0.18, difference: -0.003, $95 \%$ CI: -0.11-0.10, $p=0.96)$. The combined incentive arm participants also achieved the goal at significantly greater rates than the team incentive $(0.35$ vs. 0.17 , difference: $0.18,95 \%$ CI: $0.08-0.28, p<0.001)$, but not the individual incentive (0.35 vs. 0.25 , difference: 0.10 , $95 \%$ CI: $-0.001-0.19, p=0.05)$. Only the combined incentive had greater mean daily steps than control (difference: 1446, $95 \%$ CI: 448-2444, $p \leq 0.005$ ). There were no significant differences between arms during the follow-up period (weeks 14-26).

CONCLUSIONS: Financial incentives rewarded for a combination of individual and team performance were most effective for increasing physical activity.

TRIAL REGISTRATION: Clinicaltrials.gov identifier: NCT02001194.

KEY WORDS: behavioral economics; financial incentives; physical activity; step counts; connected health; smartphones; teams.

J Gen Intern Med 31(7):746-54

DOI: $10.1007 / \mathrm{s} 11606-016-3627-0$

(c) Society of General Internal Medicine 2016

\section{INTRODUCTION}

Physical inactivity is a major risk factor for cardiovascular disease and all-cause mortality. ${ }^{1-5}$ More than half of adults in the United States (US) do not attain the minimum recommended level of physical activity to achieve health benefits, which can be met by either 150 minutes per week of moderate activity or 75 minutes per week of more vigorous activity. ${ }^{6,7}$ The Centers for Disease Control and Prevention and many State Public Health Departments have recommended that the workplace may be a good environment to implement interventions to increase physical activity levels. ${ }^{8-11}$ However, evidence suggests that most workplace physical activity interventions are not effective, particularly for more sedentary individuals. $^{12-14}$

The importance of employer use of incentives has grown with the inclusion of a provision in the Affordable Care Act 
that significantly increases the proportion of health insurance premiums that can be used for outcome-based wellness incentives. ${ }^{15}$ More than $80 \%$ of large employers now use financial incentives for health promotion. ${ }^{16-18}$ The evaluation of financial incentives for promoting physical activity has been limited, and many of the prior studies utilize designs that are based on standard economic theory, which generally assumes individuals act rationally. ${ }^{19,20}$ Insights from behavioral economics reveal that the design and the delivery of incentives have an important influence on their effectiveness. ${ }^{21,22}$ Evidence also suggests that behavioral change programs may be more effective when individuals participate together, ${ }^{23,24}$ and when they are more socially connected. ${ }^{25,26}$ While a team-based model might enhance social incentives, ${ }^{27,28}$ the optimal combination of individual and team-based financial incentives is unknown.

In this study, our objective was to test different forms of a team-based model for promoting physical activity with financial incentives that varied the proportion of the reward that was dependent on individual vs. team performance. We used smartphones to track step counts, because more than twothirds of US adults have a smartphone ${ }^{29,30}$ most carry it with them everywhere, and our prior work has demonstrated that these devices accurately track step counts. ${ }^{31}$

\section{METHODS}

\section{Study Design}

We conducted a 26-week randomized, controlled trial between March and September 2014, consisting of a 13-week intervention period and 13-week follow-up period. Three hundred and four participants gave their informed consent, formed 4member teams and were randomly assigned as teams to control or one of three financial incentive designs (Fig. 1). All participants were given a goal of achieving at least 7000 steps per day, a target endorsed by the American College of Sports Medicine to be approximately equivalent to meeting the federal guidelines for recommended levels of physical activity to achieve health benefits. ${ }^{32,33}$ This level is $40 \%$ higher than the average daily step count of 5000 among US adults. ${ }^{34,35}$ This study was approved by the University of Pennsylvania Institutional Review Board.

\section{Setting and Participants}

Eligible participants were employees aged 18 or greater from Independence Blue Cross, a health insurance organization in Philadelphia, Pennsylvania. Many in this population had roles in which they were sitting most of the day and therefore may have been more sedentary than employees with more physically active roles. ${ }^{36,37}$ Participants were excluded if they were already participating in another physical activity study, not able or willing to carry an iPhone or Android smartphone, currently pregnant or lactating, intending to become pregnant within the next 6 months, or stated any other reason that they did not expect to be able to complete the study.

Potential participants were instructed to form a team of four members and select a captain to complete online informed consent and an eligibility screening questionnaire. The captain listed the contact information for potential teammates. All participants were asked to complete a basic sociodemographic questionnaire, self-report measures of height and weight, report physical activity in the last 7 days using the long form of the International Physical Activity Questionnaire (IPAQ), ${ }^{38}$ and to download the Moves smartphone application (ProtoGeo Oy Inc., Helsinki, Finland). Each participant was given a unique personal identification number to enter into the smartphone application and verify permission that the study team could access step count data. Once the application was installed on their phones, participants were not required to ever re-open the application, although they could as often as they wished. Instead, participants had to allow the application to run passively on their phone, and they had to have their phone powered on and had to carry it with them (e.g., in pocket, belt clip, or arm band) while they were active. Step counts were tracked during the entire day, including when outside of the work site.

\section{Randomization and Interventions}

The study was conducted using Way to Health, an automated information technology platform that has been used in prior behavioral intervention studies. ${ }^{23,39-41}$ After 76 teams completed the enrollment process, they were electronically randomized to control or one of three intervention arms: an individual incentive arm, a team incentive arm, and an arm that combined individual and team incentives. Participants in all arms received daily individual performance feedback for 26 weeks on whether the goal of at least 7000 steps was achieved on the prior day. Participants were able to choose whether to receive this feedback by email, text message, or automated voice call. The control arm received no other interventions. In the three financial incentive arms, a drawing was held every other day during the 13 -week intervention period, in which one team in each arm was chosen at random as the winning team. This design provided variable reinforcement, which has been demonstrated to be more effective for changing behavior than constant reinforcement. ${ }^{42}$ In the individual incentive arm, each participant on a winning team was eligible to collect $\$ 50$, but only if he or she had at least 7000 steps on the prior day. In the team incentive arm, each participant on the winning team was eligible to collect $\$ 50$ only if all four members of their team had each achieved at least 7000 steps on the prior day. In the combined incentive arm, each participant on the winning team was eligible to collect $\$ 20$ if he or she had at least 7000 steps on the prior day and then an additional $\$ 10$ for each team member who also had at least 7000 steps on the prior day. For example, a winning team that 


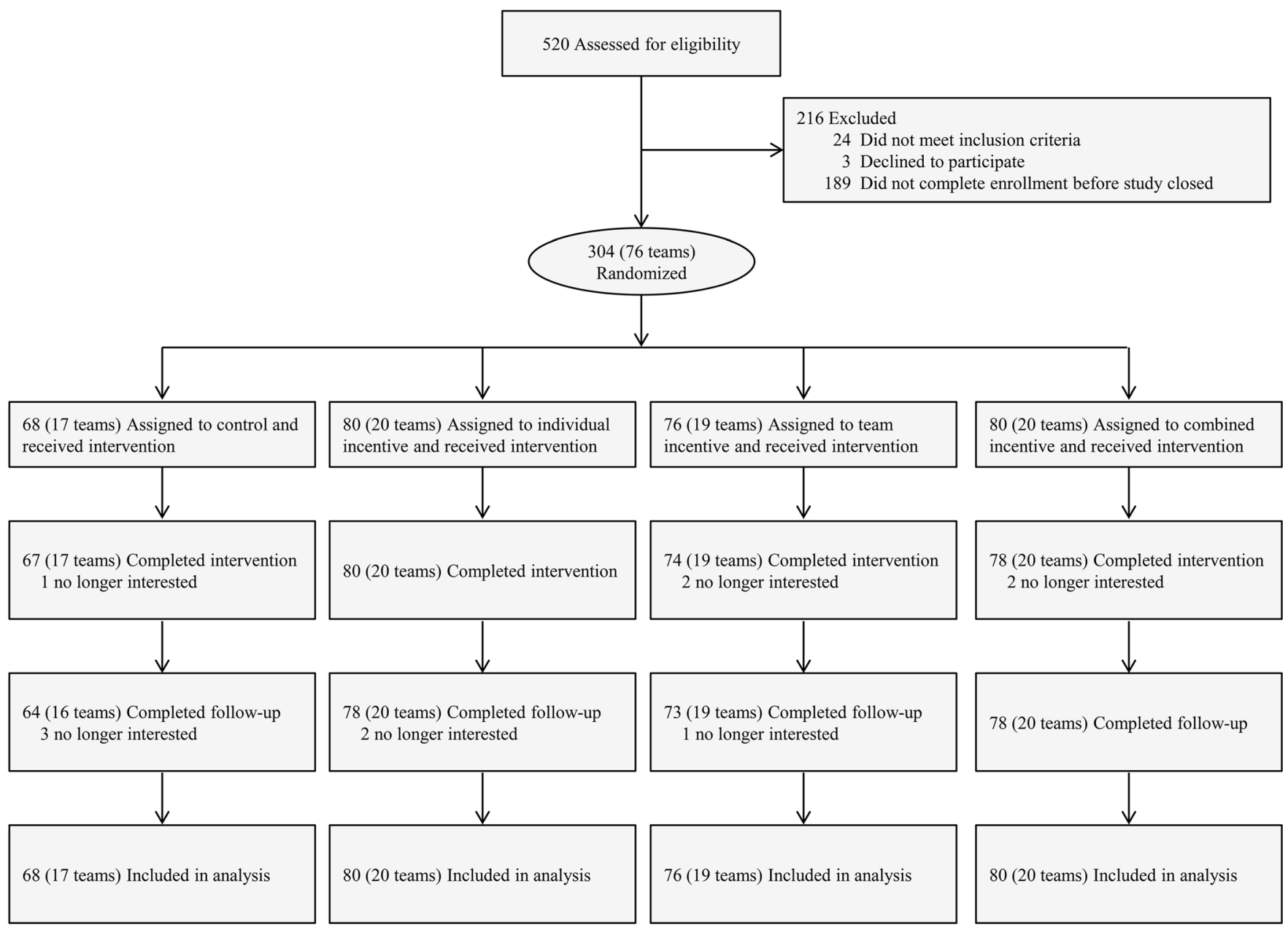

Figure 1. Study flow diagram.

had three of four members with at least 7000 steps on the prior day would result in three members receiving \$40 (\$20 for individual achievement and $\$ 20$ for the achievements of two team members) and one member receiving \$0. Participants were mailed a bank check at the end of each month with all accumulated earnings. After the intervention period, steps were monitored for an additional 13 weeks, during which daily performance feedback was continued but incentives were not.

The expected daily economic value per participant in the individual financial incentive arm was designed to be about $\$ 1.25$, a value similar to that used in a prior successful intervention. ${ }^{41}$ Participants in the team and combined incentive arms had the same maximum incentive value (\$50), but these participants could only win this amount if their teammates also achieved the step goals. A programming error in the automated drawing system resulted in random days in which no team was selected as the winner. This reduced the expected value for the individual, team, and combined incentive arms by $17 \%, 42 \%$, and $38 \%$, respectively, biasing the outcomes in all intervention arms toward the null relative to the planned design. After the follow-up period was completed, each participant was compensated for the average amount of winnings they should have but had not received over the course of the intervention period $(\$ 3.93, \$ 7.54, \$ 12.28$, respectively per participant).

\section{Outcomes and Follow-up}

The primary outcome was the mean proportion of participantdays that the 7000 step goal was achieved during the intervention period (weeks 1-13). Secondary outcomes included mean daily steps during the intervention and as well as mean proportion of participant-days achieving goal and mean daily steps during the follow-up period (weeks 14-26).

All participants received $\$ 25$ for enrolling in the study and $\$ 75$ for participating through the primary endpoint at 13 weeks. There was no participation incentive during the follow-up period. Neither the participants nor the study coordinator could be blinded to the arm assignment due to the nature of the interventions. All investigators, statisticians and data analysts were blinded to arm assignments until the entire study was completed.

\section{Statistical Analyses}

All participants randomly assigned to a study arm were included in the intention-to-treat analysis. We estimated the 
mean proportion of participant-days achieving goal in each study arm for the intervention period, the follow-up period, and for each week during the study. To adjust the standard errors for clustering by team, the mean and $95 \%$ confidence intervals were estimated using the unit of analysis as the proportion achieving goal at the level of the team. The mean daily steps were estimated for the intervention and follow-up period, with standard errors adjusted to account for clustering by team.

In the adjusted model, generalized linear mixed-models (via PROC GLIMMIX in SAS) were used to adjust for the repeated-measures of daily participant step counts and to adjust the standard errors for clustering by team. ${ }^{43-45}$ Data could be missing if a participant turned off the smartphone or Moves application, disabled the study team's permission before data was accessed, or did not carry the smartphone at all. The percentage of missing data during the intervention period was $23 \%$ for control, $18 \%$ for the individual incentive arm, $15 \%$ for the team incentive arm, and $15 \%$ for the combined incentive arm. For the main analysis, we used only collected data (a step count value was received, which assumes missing data occurs at random and does not bias outcomes for arms with differing levels of missing data. The main model included fixed effects for arm and week of the study period. Several sensitivity analyses were conducted to assess the robustness of our findings. For the primary outcome of mean proportion of participant-days achieving goal, the model was further adjusted using fixed effects for smartphone type (iPhone or Android). Second, the model was also evaluated using all data and coding missing data (when a step value was not received) as not achieving goal (in contrast to using only collected data), a method used in prior work. ${ }^{40}$ For the secondary outcome of mean daily steps, the model was further adjusted using fixed effects for smartphone type (iPhone or Android). Second, evidence suggests that step count values less than 1000 are unlikely to represent accurate data capture of actual activity. ${ }^{34,46,47}$ Therefore, to avoid these observations from biasing mean daily step outcomes, a sensitivity analysis was conducted using the model with values less than 1000 excluded from the sample. All analyses were conducted using SAS, version 9.4 (SAS Institute, Cary, North Carolina).

A priori, we estimated that a sample of at least 280 participants (70 per arm) would ensure $80 \%$ power to detect a 0.20 difference between each of the intervention arms and the control arm, using a conservative Bonferroni adjustment of the Type I error rate using a two-sided $\alpha$ of 0.017 . A secondary comparison between each of the intervention arms would require a more conservative Bonferroni adjustment of the Type I error rate using a two-sided $\alpha$ of 0.0083 . This calculation assumed that the mean proportion of participant-days achieving goal in the control arm would be 0.40 and accounted for clustering by team with an intracluster correlation coefficient of 0.025 . We increased the participant enrollment target to 304 to account for potential drop-out rate of $8 \%$ of teams.

\section{RESULTS}

Figure 1 reports trial enrollment. Participants in the control arm had a mean age slightly higher than the intervention arms; otherwise, there were no significant differences in participant baseline characteristics across the four study arms (Table 1).

The mean proportion of participant-days achieving the 7000 steps goal peaked at about 0.45 in the combined incentive arm and 0.33 in the individual incentive arm, but was never greater than 0.23 in the team incentive arm or control. These levels declined over the intervention period for all arms (Fig. 2). Compared to control during the intervention period, the mean proportion of participant-days achieving the 7000 step goal was significantly greater for the combined incentive ( 0.35 vs. 0.18 , difference: $0.17,95 \%$ confidence interval [CI]: $0.07-0.28, p<0.0,01)$ but not for the individual incentive (0.25 vs 0.18 , difference: $0.08,95 \% \mathrm{CI}:-0.02-0.18$, $p=0.13)$ or the team incentive ( 0.17 vs 0.18 , difference: $-0.003,95 \%$ CI: $-0.11-0.10, p=.96)$. The combined incentive was also significantly greater than the team incentive $(0.35$ vs. 0.17 , difference: $0.18,95 \%$ CI: $0.08-0.28, p<0.001)$, but not the individual incentive ( 0.35 vs. 0.25 , difference: $0.10,95 \%$ CI: $-0.001-0.19, p=0.05)$. In the main adjusted model during the intervention period, the combined incentive arm had higher odds of achieving goal compared to the control arm (Odds Ratio [OR]: 3.54, $95 \%$ CI: 1.56-8.06, $p=0.003$ ) and the team-based incentive arm (OR: 3.02, $95 \%$ CI: 1.37-6.68, $p=0.006$ ) (Table 2).

Compared to the control group during the intervention period, the mean daily steps were significantly greater for the combined incentive (5280 vs. 3929 , adjusted difference: 1446 , $95 \%$ CI: 448-2444, $p=0.005)$, but not for the individual incentive (4516 vs. 3929 , adjusted difference: $602,95 \%$ CI: $-393-1596, p=0.24$ ) or the team incentive (3930 vs. 3929 , adjusted difference: 193, $95 \%$ CI: $-819-1205, p=0.71$ ) (Table 3).

The patterns observed during the intervention period were qualitatively similar during the follow-up period, but there were no longer significant differences compared to control. Results were qualitatively similar in sensitivity analyses to that of the main model for all outcomes.

\section{DISCUSSION}

This study used a team-based model and demonstrated that an incentive structure that provides rewards based on a combination of individual and team performance was most effective for increasing physical activity in the sample population.

These findings expand understanding of using team-based models and financial incentives for changing health behaviors. A study by Wing and colleagues evaluated a statewide intervention using a team-based model in a 16 -week competition. ${ }^{48}$ Over 4700 participants formed teams ranging in size from five to 11 persons and selected whether they wanted to compete for the most weight loss, step counts, or hours of exercise. 
Table 1. Characteristics of Study Participants

\begin{tabular}{|c|c|c|c|c|c|}
\hline Characteristic & $\begin{array}{l}\text { Control } \\
(\mathrm{n}=17 \text { teams, } \\
68 \text { participants) }\end{array}$ & $\begin{array}{l}\text { Individual Incentive } \\
(\mathrm{n}=\mathbf{2 0} \text { teams, } \\
\mathbf{8 0} \text { participants })\end{array}$ & $\begin{array}{l}\text { Team Incentive } \\
(\mathrm{n}=19 \text { teams, } \\
76 \text { participants) }\end{array}$ & $\begin{array}{l}\text { Combined Incentive } \\
(\mathrm{n}=20 \text { teams, } \\
80 \text { participants })\end{array}$ & $\overline{p \text { Value }}$ \\
\hline Female Gender, n (\%) & $51(75.0)$ & $62(77.5)$ & $65(85.5)$ & $57(71.3)$ & 0.19 \\
\hline Age, mean (SD) & $43.2(10.0)$ & $39.3(10.2)$ & $38.7(10.2)$ & $41.2(10.8)$ & 0.04 \\
\hline \multicolumn{6}{|l|}{ Self-reported baseline measures } \\
\hline Body mass index, mean (SD) & $29.0(6.7)$ & $29.9(6.3)$ & $28.1(6.4)$ & $29.7(6.2)$ & 0.31 \\
\hline $\begin{array}{l}\text { Physical activity in the last } 7 \text { days } \\
\text { (MET-min), Median (IQR) }\end{array}$ & $\begin{array}{l}4220.8 \\
(2001.3,6708.0)\end{array}$ & $\begin{array}{l}3510.0 \\
(1704.0,5875.5)\end{array}$ & $\begin{array}{l}3486.0 \\
(2214.0,5328.0)\end{array}$ & $\begin{array}{l}2967.0 \\
(1465.0,4904.3)\end{array}$ & 0.70 \\
\hline \multicolumn{5}{|l|}{ Race/Ethnicity, n (\%) } & \multirow[t]{5}{*}{0.09} \\
\hline White non-Hispanic & $38(55.9)$ & $30(37.5)$ & $43(56.6)$ & $50(62.5)$ & \\
\hline African American non-Hispanic & $22(32.4)$ & 37 (46.3) & $23(30.3)$ & $19(23.8)$ & \\
\hline Other non-Hispanic & $3(4.4)$ & $9(11.3)$ & $6(7.9)$ & $8(10.0)$ & \\
\hline Hispanic & $5(7.4)$ & $4(5.0)$ & $3(3.9)$ & $3(3.8)$ & \\
\hline \multicolumn{5}{|l|}{ Education, n (\%) } & \multirow{4}{*}{0.73} \\
\hline Less than college & $2(2.9)$ & $7(8.8)$ & $6(7.9)$ & $7(8.8)$ & \\
\hline Some college & $20(29.4)$ & $23(23.8)$ & $26(34.2)$ & $21(26.3)$ & \\
\hline College graduate & $45(66.2)$ & $50(62.5)$ & $44(57.9)$ & $52(65.0)$ & \\
\hline \multicolumn{5}{|l|}{ Marital status, n (\%) } & \multirow[t]{4}{*}{0.12} \\
\hline Single & $28(41.2)$ & $43(58.8)$ & $33(43.4)$ & $26(32.5)$ & \\
\hline Married & $35(51.5)$ & $29(36.3)$ & $32(42.1)$ & $41(51.3)$ & \\
\hline Other & $5(7.4)$ & $8(10.0)$ & $11(14.5)$ & $13(16.3)$ & \\
\hline \multicolumn{5}{|l|}{ Annual household income, n (\%) } & \multirow[t]{4}{*}{0.08} \\
\hline Less than $\$ 50,000$ & $21(26.3)$ & $21(26.3)$ & $13(17.1)$ & $11(13.8)$ & \\
\hline$\$ 50,000$ to $\$ 100,000$ & $34(42.5)$ & $34(42.5)$ & $38(50.0)$ & $34(42.5)$ & \\
\hline Greater than $\$ 100,000$ & $18(22.5)$ & $18(22.5)$ & $21(27.6)$ & $30(37.5)$ & \\
\hline iPhone Smartphone, n (\%) & $40(50.8)$ & $47(58.8)$ & $43(56.6)$ & $55(68.8)$ & 0.40 \\
\hline
\end{tabular}

$M E T=$ metabolic equivalent of task, a measure of energy expenditure; $I Q R=$ interquartile range

Participants or their employers paid $\$ 15$ per person to enter and competitions were held every 2 weeks. Winners received verbal praise and commendation but no other prizes. Among the $70 \%$ that completed the study, mean weight loss was $3.2 \mathrm{~kg}$ and $30 \%$ of them lost more than $5 \%$ of their initial weight. Greater weight loss was associated with higher steps per day and hours of exercise. However, this study was limited in that data was mostly self-reported, there was no control group for comparison, and the main analysis did not include the nearly one-third of participants that failed to complete the program. Prior work using a randomized, controlled trial with 105 obese participants found that financial incentives for weight loss were more effective for groups of participants when compared to individuals alone or control. ${ }^{23}$ After 24 weeks, group participants lost $4.4 \mathrm{~kg}$ more than control and $3.2 \mathrm{~kg}$ more than the individual arm participant. After an additional 12 weeks of follow-up without incentives, group participants had still lost $2.9 \mathrm{~kg}$ more than control. However, in that study, participants were blinded to the identities of other members and could on average earn higher rewards if other group members did not meet the goal. In comparison, the team-based model tested here was designed to increase an individual's accountability to the teammates with whom they signed up for the program and the maximal value that could be

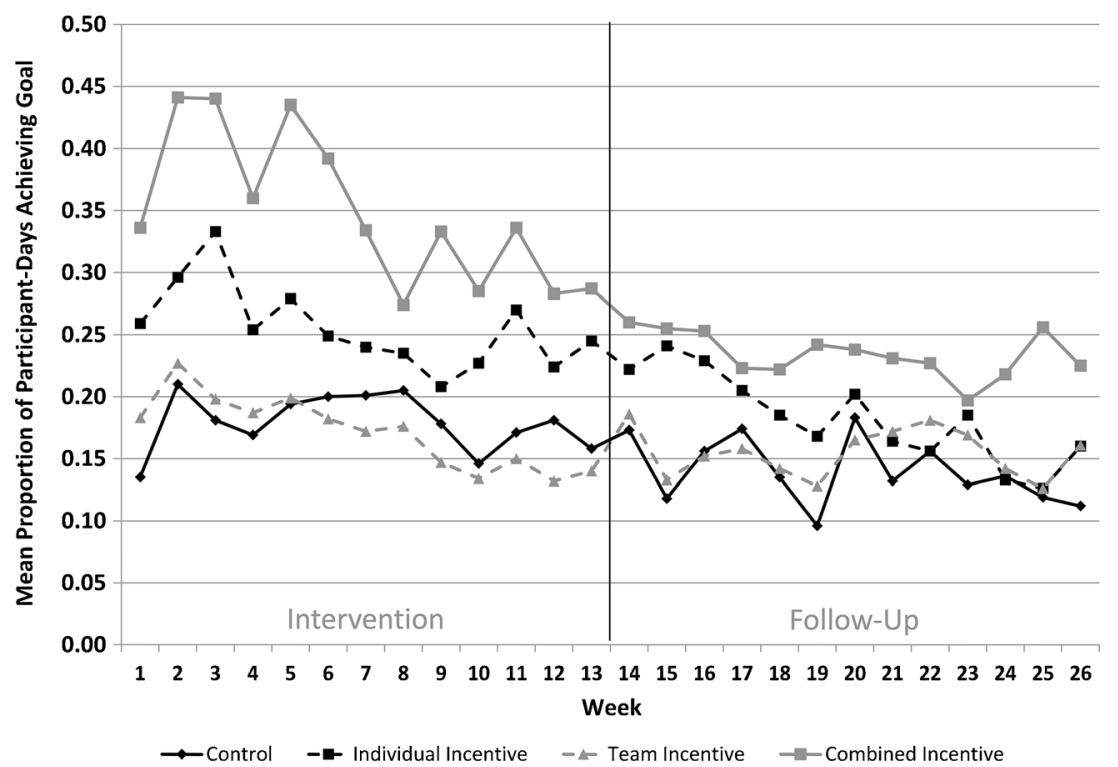

Figure 2. Unadjusted mean proportion of participant-days achieving the 7000 step goal, displayed by study arm for each week of the study. 
Table 2. Adjusted Odds of Achieving the 7000 Step Goal During the Intervention and Follow-up Periods

\begin{tabular}{|c|c|c|c|c|c|}
\hline \multirow[t]{2}{*}{ Model $^{*}$} & \multirow[t]{2}{*}{ Arm Comparison } & \multicolumn{2}{|l|}{$\begin{array}{l}\text { Intervention } \\
\text { (Weeks 1- 13) }\end{array}$} & \multicolumn{2}{|l|}{$\begin{array}{l}\text { Follow-up } \\
\text { (Weeks 14-26) }\end{array}$} \\
\hline & & $\begin{array}{l}\text { Odds Ratio } \\
\text { (95\% CI) }\end{array}$ & $p$ Value & $\begin{array}{l}\text { Odds Ratio } \\
\text { (95\% CI) }\end{array}$ & $p$ Value \\
\hline \multirow[t]{6}{*}{ Main Model } & Individual incentive vs. control & $1.72(0.76,3.93)$ & 0.19 & $1.27(0.55,2.96)$ & 0.58 \\
\hline & Team incentive vs. control & $1.17(0.51,2.71)$ & 0.71 & $1.01(0.43,2.38)$ & 0.98 \\
\hline & Combined incentive vs. control & $3.54(1.56,8.06)$ & 0.003 & $1.72(0.74,4.00)$ & 0.21 \\
\hline & Team incentive vs. individual incentive & $0.68(0.31,1.49)$ & 0.34 & $0.79(0.35,1.82)$ & 0.58 \\
\hline & Combined incentive vs. individual incentive & $2.04(0.94,4.55)$ & 0.07 & $1.35(0.60,3.03)$ & 0.47 \\
\hline & Combined incentive vs. team incentive & $3.02(1.37,6.68)$ & 0.006 & $1.70(0.75,3.86)$ & 0.20 \\
\hline \multirow[t]{6}{*}{ Main Model_-Adjusted by device } & Individual incentive vs. control & $1.77(0.80,3.94)$ & 0.16 & $1.23(0.53,2.85)$ & 0.62 \\
\hline & Team incentive vs. control & $1.23(0.55,2.78)$ & 0.61 & $1.03(0.44,2.40)$ & 0.95 \\
\hline & Combined incentive vs. control & $3.44(1.55,7.64)$ & 0.002 & $1.63(0.71,3.76)$ & 0.25 \\
\hline & Team incentive vs. individual incentive & $0.69(0.32,1.49)$ & 0.36 & $0.83(0.37,1.89)$ & 0.66 \\
\hline & Combined incentive vs. individual incentive & $1.96(0.92,4.17)$ & 0.08 & $1.32(0.60,2.94)$ & 0.49 \\
\hline & Combined incentive vs. team incentive & $2.79(0.55,2.78)$ & 0.009 & $1.59(0.71,3.57)$ & 0.26 \\
\hline \multirow{6}{*}{$\begin{array}{l}\text { Main Model_-Adjusted by } \\
\text { device and with missing data as } \\
\text { not achieving goal }\end{array}$} & Individual incentive vs. control & $2.03(0.94,4.42)$ & 0.07 & $1.17(0.51,2.71)$ & 0.71 \\
\hline & Team incentive vs. control & $1.43(0.65,3.15)$ & 0.37 & $1.09(0.47,2.53)$ & 0.84 \\
\hline & Combined incentive vs. control & $3.57(1.65,3.00)$ & 0.001 & $1.55(0.67,3.56)$ & 0.30 \\
\hline & Team incentive vs. individual incentive & $0.70(0.33,1.49)$ & 0.36 & $0.93(0.41,2.08)$ & 0.86 \\
\hline & Combined incentive vs. individual incentive & $1.75(0.84,3.70)$ & 0.13 & $1.32(0.59,2.94)$ & 0.50 \\
\hline & Combined incentive vs. team incentive & $2.49(1.18,5.25)$ & 0.02 & $1.42(0.63,3.19)$ & 0.39 \\
\hline
\end{tabular}

${ }^{*}$ Main model adjusts for repeated measures of daily participant step counts and for temporal trends by week using all collected data. Outcome measure is a binary term (0 or 1) based on not achieving or achieving goal

vs. = versus; $C I=$ confidence interval; device refers to type of smartphone

Grey highlighting indicates meeting significance threshold of $p<0.0167$ for primary comparison to control and $p<0.0083$ for secondary comparison between arms

Odds ratios represent the ratio of odds of achieving the 7000 step goal for a participant on a random day during either the intervention period (third column) or follow-up period (fourth column) if that participant's team were to be assigned to the one specified study arm vs. the other specified study arm

won was the same across study arms. The collaborative rather than competitive design may also enhance the team's unity toward achieving a common goal.

Prior work found that a combination of individual and teambased rewards was effective in increasing engagement in a one-time health promotion activity - completion of a health risk assessment (HRA). ${ }^{24}$ In that intervention, if a given team had their lottery number chosen, individuals within that team would receive $\$ 100$ if they personally completed an HRA, with this amount increased to $\$ 125$ if more than $80 \%$ of their team members did. This study builds upon that prior work, and enhances our understanding of designing individual vs. team-

Table 3. Adjusted Daily Step Differences Between Study Arms During the Intervention and Follow-up Periods

\begin{tabular}{|c|c|c|c|c|c|}
\hline \multirow[t]{2}{*}{ Model" $^{\prime \prime}$} & \multirow[t]{2}{*}{ Arm Comparison } & \multicolumn{2}{|l|}{$\begin{array}{l}\text { Intervention } \\
\text { (Weeks 1-13) }\end{array}$} & \multicolumn{2}{|l|}{$\begin{array}{l}\text { Follow-up } \\
\text { (Weeks 14- 26) }\end{array}$} \\
\hline & & $\begin{array}{l}\text { Difference } \\
\text { in Daily Steps } \\
(95 \% \text { CI })\end{array}$ & $p$ Value & $\begin{array}{l}\text { Difference in } \\
\text { Daily Steps } \\
(95 \% \text { CI) }\end{array}$ & $p$ Value \\
\hline \multirow[t]{6}{*}{ Main Model } & Individual incentive vs. control & $602(-393,1596)$ & 0.24 & $405(-668,1479)$ & 0.46 \\
\hline & Team incentive vs. control & $193(-819,1205)$ & 0.71 & $10(-1063,1084)$ & 0.98 \\
\hline & Combined incentive vs. control & $1446(448,2444)$ & 0.005 & $1077(7,2146)$ & 0.049 \\
\hline & Team incentive vs. individual incentive & $-409(-1370,553)$ & 0.40 & $-395(-1433,643)$ & 0.46 \\
\hline & Combined incentive vs. individual incentive & $844(-102,1791)$ & 0.08 & $671(-363,1705)$ & 0.20 \\
\hline & Combined incentive vs. team incentive & $1253(288,2218)$ & 0.01 & $1066(32,2100)$ & 0.04 \\
\hline \multirow{6}{*}{ Main Model_-Adjusted by device } & Individual incentive vs. control & $628(-322,1577)$ & 0.20 & $372(-675,1420)$ & 0.49 \\
\hline & Team incentive vs. control & $264(-702,1231)$ & 0.59 & $41(-1006,1088)$ & 0.94 \\
\hline & Combined incentive vs. control & $1378(424,2331)$ & 0.005 & $985(-60,2029)$ & 0.06 \\
\hline & Team incentive vs. individual incentive & $-364(-1282,554)$ & 0.44 & $-332(-1345,682)$ & 0.52 \\
\hline & Combined incentive vs. individual incentive & $750(-155,1654)$ & 0.10 & $612(-397,1622)$ & 0.23 \\
\hline & Combined incentive vs. team incentive & $1113(190,2037)$ & 0.02 & $944(-67,1955)$ & 0.07 \\
\hline \multirow{6}{*}{$\begin{array}{l}\text { Main Model_-Adjusted by device } \\
\text { and excluding step counts less } \\
\text { than } 1000\end{array}$} & Individual incentive vs. control & $632(-254,1518)$ & 0.16 & $381(-587,1349)$ & 0.44 \\
\hline & Team incentive vs. control & $302(-601,1205)$ & 0.51 & $98(-870,1065)$ & 0.84 \\
\hline & Combined incentive vs. control & $1227(339,2115)$ & 0.01 & $815(-148,1779)$ & 0.10 \\
\hline & Team incentive vs. individual incentive & $-330(-1184,524)$ & 0.45 & $-284(-1221,653)$ & 0.55 \\
\hline & Combined incentive vs. individual incentive & $595(-244,1435)$ & 0.16 & $434(-498,1366)$ & 0.36 \\
\hline & Combined incentive vs. team incentive & $925(67,1783)$ & 0.03 & $718(-215,1651)$ & 0.13 \\
\hline
\end{tabular}

* Main model adjusts for repeated measures of daily participant step counts and for temporal trends by week using all collected data vs. = versus; $C I=$ confidence interval; device refers to type of smartphone

Values are presented as the difference between the intervention arm and control; $C I=$ confidence interval

Grey highlighting indicates meeting significance threshold of $p<0.0167$ for primary comparison to control and $p<0.0083$ for secondary comparison between arms 
based financial incentives to achieve higher peak levels of performance in the short-term for achieving a minimum level of daily physical activity, an example of a behavior that requires ongoing effort and sustained engagement. These new insights develop evidence that can be built upon in future studies to further refine incentive design to focus on longerterm outcomes.

There are several important implications for the design of physical activity interventions and wellness programs more broadly. First, physical activity interventions have often been challenged by the need to accurately measure and record data from daily behaviors. ${ }^{49-52}$ Prior studies have relied mostly on either self-reported activity. ${ }^{52}$ In this study, physical activity was measured using smartphones, which are already in possession by two-thirds of US adults, ${ }^{29,30}$ but have not previously been well evaluated. ${ }^{53}$ Our study demonstrates that using smartphones for activity tracking may be a scalable method to deploy physical activity interventions in real-word settings.

Second, while technology may help to facilitate monitoring of outcomes, it is the behavioral intervention strategies that will be critical to driving ongoing engagement and behavior change. ${ }^{27}$ Financial incentives in this study were designed using insights from behavioral economics to leverage individuals' tendencies to avoid regret, overestimate small probabilities, and to be more engaged by variable reinforcement. ${ }^{21,22,54}$ Our finding that the combined incentive was most effective suggests that team-based incentives may be better designed if they balance rewarding individual accomplishments and reinforcing accountability and peer support to the team. While individual rewards have been shown in a variety of contexts to be effective, they may have been less effective here because in the context of a team-based structure they did not provide adequate social reinforcement. ${ }^{24,27,48}$

Third, while sedentary individuals may benefit the most from increased physical activity and the workplace may be an important setting to identify and target these individuals, ${ }^{8-14}$ there is a lack of evidence of effective programs to change sedentary behaviors. ${ }^{55-57}$ In this study, participants in the control arm had mean daily step counts below the national average, supporting our hypothesis that this study population may be more sedentary. ${ }^{36,37}$ Among participants in this study, $70 \%$ had a $\mathrm{BMI}>25$ (overweight) and $39 \%$ had a BMI $>30$ (obese); further indication that these participants may be relatively sedentary. ${ }^{58}$ Nevertheless, participants had a high engagement rate: $96.4 \%$ of them completed the 26-week study despite no financial incentive of any kind during the follow-up period. This success may be due to the smartphone-based approach to data collection, which required little additional individual effort.

Future studies might compare different methods of using combined incentives to test the optimal magnitude and frequency of incentives. Social incentives such as accountability and peer support may be further tested by comparing team- based designs (such as those used in this study) to participating alone. While step counts are an important metric of activity, future studies might test physical activity programs that increase activity duration and allow for other types of activity besides steps such as swimming or biking.

Our study is subject to several limitations. First, participants were from a single organization in the same city, which may limit generalizability. Second, participants in this study were required to have a smartphone, potentially making participation less accessible to those without these devices. Third, participants' physical activity was not tracked when they were not carrying their smartphones, and captured physical activity levels may be lower than actual activity. In addition, we assumed that the smartphones were only carried by the participants themselves. However, at the end of the intervention period, about $92 \%$ of respondents stated that they carried their smartphone most or all of the time. Fourth, we did not obtain data on baseline step counts; however, randomization resulted in study arms that were well balanced, and therefore outcomes between arms may well reflect the differential effectiveness of interventions. In addition, self-reported physical activity did not differ between arms; however, these data appear to reflect over-estimates of baseline activity as study outcome data reflect that this is a more sedentary population than participants initially reported. Fifth, as previously noted, a programming error led to winning frequencies lower than intended. If participants adjusted their expectations based on the rate at which they won, incentive arm participants could be less motivated to walk relative to how much they might have walked if the incentive were delivered as designed. However, these differences were subtle and likely imperceptible to participants, given the small differences in payout amounts. This error is conservative in its main effect, strengthening the observation that the combined incentive is superior to control, but tempering our ability to draw definitive conclusions about the effectiveness of the individual and team incentives when used alone. Sixth, physical activity levels peaked early during the intervention period and then declined over the rest of the study for all arms. Further study is necessary to determine how to sustain higher rates of physical activity over a longer time period.

\section{CONCLUSIONS}

Despite many associated health benefits, less than half of adults in the US attain the minimum recommended level of physical activity. In this study, a team-based physical activity intervention using a combination of individual and team incentives nearly doubled the mean proportion that achieved the goal during the intervention period. Our findings may give promise to using smartphones to track outcomes in behavioral interventions, and should be evaluated in broader populations to inform scalable applications to increase physical activity. 
Acknowledgements: This work was funded by the National Institute on Aging (RC4 AG039114) to Drs. Asch and Volpp. Drs. Patel, Asch and Volpp were supported in part by the Department of Veteran Affairs and Drs. Patel and Asch were supported in part by the Robert Wood Johnson Foundation. The funding sources had no role in the design and conduct of the study; collection, management, analysis, and interpretation of the data; and preparation, review, or approval of the manuscript; and decision to submit the manuscript for publication. Dr. Patel had full access to all the data in the study and takes responsibility for the integrity of the data and the accuracy of the data analysis.

Corresponding Author: Mitesh S. Patel, MD, MBA, MS; Perelman School of MedicineUniversity of Pennsylvania, Philadelphia, PA, USA (e-mail: mpatel@upenn.edu).

\section{Compliance with Ethical Standards:}

Conflicts of Interest: Dr. Volpp and Dr. Asch are principals at the behavioral economics consulting firm, VAL Health. Dr. Volpp also has received consulting income from CVS Caremark and research funding from Humana, CVS Caremark, Discovery (South Africa), and Merck, none of which are related to the work described in this manuscript. The authors declare no other conflicts of interest.

\section{REFERENCES}

1. Bijnen FC, Caspersen CJ, Mosterd WL. Physical inactivity as a risk factor for coronary heart disease: a WHO and International Society and Federation of Cardiology position statement. Bull World Health Organ. 1994;72(1):1-4.

2. Murphy SL, Xu JQ, Kochanek KD. Deaths: Final data for 2010. National vital statistics reports. Hyattsville (MD): National Center for Health Statistics; 2013;61(4).

3. Shiroma EJ, Lee IM. Physical activity and cardiovascular health: lessons learned from epidemiological studies across age, gender, and race/ ethnicity. Circulation. 2010;122(7):743-752.

4. Lee I-M, Shiroma EJ, Lobelo F, Puska P, Blair SN, Katzmarzyk PT. Impact of physical activity on the world's major non-communicable disease. Lancet. 2012;380(9838):219-229.

5. Yang Q, Cogswell ME, Flanders WD, Hong Y, Zhang Z, Loustalot F, Gillespie C, Merritt R, Hu FB. Trends in cardiovascular health metrics and associations with all-cause and CVD mortality among US adults. JAMA. 2012;307(12):1273-1283.

6. Centers for Disease Control and Prevention. Facts about physical activity. Available online at: http://www.cdc.gov/physicalactivity/data/facts.html. Accessed November 26, 2014.

7. Go AS, Mozaffarian D, Roger VL, Benjamin EJ, Berry JD, Borden WB, et al.On behalf of the American Heart Association Statistics Committee and Stroke Statistics Subcommittee. Heart disease and stroke statistics-2013 update: a report from the American Heart Association. Circulation. 2013; 127:e6-e245.

8. Centers for Disease Control and Prevention. Steps to wellness. A guide to implementing the 2008 physical activity guidelines for Americans in the workplace. Available online at, http://www.cdc.gov/nccdphp/dnpao/hwi/ downloads/Steps2Wellness_BROCH14_508_Tag508.pdf. Accessed January 19, 2015.

9. California Department of Public Health. Worksite program California fit business kit. Available online at: http://www.cdph.ca.gov/programs/ cpns/pages/worksitefitbusinesskit.aspx. Accessed January 19, 2015.

10. Texas Department of State Health Services. Worksite wellness resources. Available online at: https://www.dshs.state.tx.us/wellness/ worksiteresources.shtm. Accessed January 19, 2015.

11. Wisconsin Department of Health Services. Nutrition and physical activity resources. Available online at: https://www.dhs.wisconsin.gov/physicalactivity/worksite/index.htm. Accessed January 19, 2015.

12. Dishman RK, Oldenburg B, O'Neal H, Shephard RJ. Worksite physical activity interventions. Am J Prev Med. 1998;15(4):344-361.

13. Bravata DM, Smith-Spangler C, Sundaram V, Gienger AL, Lin N, Lewis R. Using pedometers to increase physical activity and improve health: a systematic review. JAMA. 2007;298(19):2296-2304.

14. Conn VS, Hafdahl AR, Cooper PS, Brown LM, Lusk SL. Meta-analysis of workplace physical activity interventions. Am J Prev Med. 2009;37(4):330339.
15. Madison K, Schmidt H, Volpp KG. Smoking, obesity, health insurance, and health incentives in the Affordable Care Act. JAMA. 2013;310(2):143-144.

16. Towers Watson. Employer survey on purchasing value in health care. Available online at: http://www.towerswatson.com/en-US/Insights/ICTypes/Survey-Research-Results /2014/05/full-report-towers-watsonnbgh-2013-2014-employer-survey-on-purchasing-value-in-health-care. Accessed December 30, 2014.

17. National Business Group on Health/Fidelity Investments' Annual Employer-Sponsored Health \& Well-being Survey. Available online at: https://www.businessgrouphealth.org/benchmarking/surveyreports.cfm. Accessed April 20, 2015.

18. 2014 Employer Health Benefits Survey. Kaiser Family Foundation. Available online at: http://kff.org/health-costs/report/2014-employerhealth-benefits-survey/. Accessed April 20, 2015.

19. Mitchell MS, Goodman JM, Alter DA, John LK, Oh PI, Pakosh MT, et al. Financial incentives for exercise adherence in adults. Am $J$ Prev Med. 2013;45(5):658-667.

20. Finkelstein EA, Brown DS, Brown DR, Buchner DM. A randomized study of financial incentives to increase physical activity among sedentary older adults. Prev Med. 2008;47:182-187.

21. Loewenstein G, Brennan T, Volpp KG. Asymmetric paternalism to improve health behaviors. JAMA. 2007;298(20):2415-2417.

22. Loewenstein G, Asch DA, Volpp KG. Behavioral economics holds potential to deliver better results for patients, insurers, and employers. Health Aff. 2013;32(7):1244-1250.

23. Kullgren JT, Troxel AB, Loewenstein G, Asch DA, Norton LA, Wesby L, Tao Y, Zhu J, Volpp KG. Individual- versus group-based financial incentives for weight loss: a randomized, controlled trial. Ann Intern Med. 2013; 158(7):505-514.

24. Haisley E, Volpp KG, Pellathy T, Loewenstein G. The impact of alternative incentive schemes on completion of health risk assessments. Am J Health Promot. 2012;26(3):184-188.

25. Jackson SE, Steptoe A, Wardle J. The Influence of Partner's Behavior on Health Behavior Change: The English Longitudinal Study of Ageing. JAMA Intern Med. 2015;175(3):385-92.

26. Christakis NA, Fowler JH. The spread of obesity in a large social network over 32 years. N Engl J Med. 2007;357(4):370-9.

27. Patel MS, Asch DA, Volpp KG. Wearable devices as facilitators, not drivers, of health behavior change. JAMA. 2015;313(5):459-460.

28. Centers for Disease Control and Prevention. Workplace Health Program. Available online at: http://www.cdc.gov/workplacehealthpromotion/implementation/topics/physical-activity.html. Accessed April 9. 2015.

29. Nieslen. The U.S. digital consumer report. February 10, 2014. Available online at: http://www.nielsen.com/us/en/insights/reports/2014/the-usdigital-consumer-report.html. Accessed November 17, 2014.

30. United States Census Bureau. Computer and internet use in the United States: 2013. Available online at: http://www.census.gov/content/dam/Census/library/publications/2014/acs/acs-28.pdf. Accessed December 1, 2014.

31. Case MA, Burwick HA, Volpp KG, Patel MS. The accuracy of smartphone applications and wearable devices for tracking physical activity data. JAMA. 2015;313(6):625-626.

32. Garber CE, Blissmer B, Deschenes MR, Franklin BA, Lamonte MJ, Lee I, et al. on behalf of the American College of Sports Medicine. Quantity and quality of exercise for developing and maintaining cardiorespiratory, musculoskeletal, and neuromotor fitness in apparently health adults: Guidance for prescribing exercise. Med Sci Sports Exerc. 2011;43(7): 1334-1359.

33. United States Department of Health and Human Services. 2008 physical activity guidelines for Americans. Hyattsville: US Department of Health and Human Services; 2008.

34. Bassett DR, Wyatt HR, Thompson H, Peters JC, Hill Jo. Pedometermeasured physical activity and health behaviors in U.S. adults. Med Sci Sports Exerc. 2010;42(10):1819-1825.

35. Sisson SB, Camhi SM, Tudor-Locke C, Johnson WD, Katzmarzyk PT. Characteristics of step-defined physical activity categories in U.S. adults. Am J Health Promot. 2012;26(3):152-159.

36. Jans MP, Proper KI, Hildebrandt VH. Sedentary behavior in Dutch workers: differences between occupations and business sectors. Am J Prev Med. 2007;33(6):450-454.

37. Vandelanotte C, Duncan MJ, Short C, Rockloff M, Ronan K, Happell B, Di Milia L. Associations between occupational indicators and total, workbased and leisure-time sitting: a cross-sectional study. BMC Public Health. 2013;13(1): 1110 .

38. Craig CL, Marshall AL, Sjostrom M, Bauman AE, Booth ML, Ainsworth $\mathbf{B E}$, et al. International physical activity questionnaire: 12-country reliability and validity. Med Sci Sports Exerc. 2003;35:1381-1395. 
39. Asch DA, Volpp KG. On the Way to Health. LDI Issue Brief. 2012;17(9):1-4.

40. Kullgren JT, Harkins KA, Bellamy SL, Gonzales A, Tao Y, Zhu J, Volpp KG, Asch DA, Heisler M, Karlawish J. A mixed-methods randomized controlled trial of financial incentives and peer networks to promote walking among older adults. Health Educ Behav. 2014;41(1 Suppl):43S-50S.

41. Sen AP, Sewell TB, Riley EB, Stearman B, Bellamy SL, Hu MF, Tao Y, Zhu J, Park JD, Loewenstein G, Asch DA, Volpp KG. Financial incentives for home-based health monitoring: a randomized controlled trial. J Gen Intern Med. 2014;29(5):770-777.

42. Miltenberger RG. Behavioral Modification: Principles and Procedures. Belmont (CA): Thomson Wadsworth; 2008.

43. Breslow NE, Clayton DG. Approximate Inference in Generalized Linear Mixed Models. J Am Stat Assoc. 1993;88:9-25.

44. Schabenberger O, Gregoire TG. Population-averaged and Subject-specific Approaches for Clustered Categorical Data. J Stat Comput Simul. 1996;54:231-253.

45. SAS Institute Inc., SAS 9.4 Help and Documentation. Cary (NC): SAS Institute Inc., 2002-2004.

46. Rowe DA, Mahar MT, Raedeke TD, Lore J. Measuring physical activity in children with pedeometers: Reliability, reactivity, and replacement of missing data. Pediatr Exerc Sci. 2004;16:1-12.

47. Kang M, Zhu W, Tudor-Locke C, Ainsworth B. Experimental determination of effectiveness of an individual information-centered approach in recovering step-count missing data. Meas Phys Educ Exerc Sci. 2004;9(4):233-250.

48. Wing RR, Pinto AM, Crane MM, Kumar R, Weinberg BM, Gorin AA. A statewide intervention reduces BMI in adults: Shape Up Rhode Island results. Obesity. 2009; 17(5):991-995.

49. Dishman RK. The measurement conundrum in exercise adherence research. Med Sci Sports Exerc. 1994;26(11):1382-1390.
50. LaPorte RE, Montoye HJ, Caspersen CJ. Assessment of physical activity in epidemiologic research: problems and prospects. Public Health Rep. 1985; 100(2): 131-146.

51. Seefeldt V, Malina RM, Clark MA. Factors affecting levels of physical activity in adults. Sports Med. 2002;32(3):143-168.

52. Strath SJ, Kaminsky LA, Ainsworth BE, Ekelund U, Freedson PS, Gary RA, et al. Guide to the assessment of physical activity: clinical and research applications: a scientific statement from the American Heart Association. Circulation. 2013;128(20):2259-2279.

53. Bort-Roig J, Gilson ND, Puig-Ribera A, Contreras RS, Trost SG. Measuring and influencing physical activity with Smartphone technology: a systematic review. Sports Med. 2014;44(5):671-686.

54. Volpp KG, Asch DA, Galvin R, Loewenstein G. Redesigning employee health incentives-lessons from behavioral economics. N Engl J Med. 2011;365(5):388-390.

55. Tudor-Locke CE, Myers AM. Challenges and opportunities for measuring physical activity in sedentary adults. Sports Med. 2001;31(2):91-100.

56. Orrow G, Kinmonth AL, Sanderson S, Sutton S. Effectiveness of physical activity promotion based in primary care: systematic review and meta-analysis of randomised controlled trials. Br J Sports Med. 2013;47(1):27.

57. Mozaffarian D, Afshin A, Benowitz NL, Bittner V, Daniels SR, Franch HA, et al. Population approaches to improve diet, physical activity, and smoking habits: a scientific statement from the American Heart Association. Circulation. 2012;126(12):1514-1563.

58. Pietilainen KH, Kaprio J, Borg P, Plasqui G, Yki-Jarvinen H, Kujala UM, et al. Physical inactivity and obesity: a vicious cycle. Obesity. 2008; 16(2):409-414. 